The Israeli Journal of Aquaculture - Bamidgeh, IJA_69.2017.1370, 7 pages

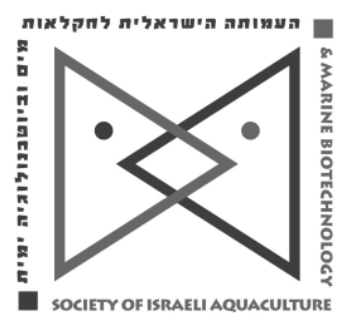

The IJA appears exclusively as a peer-reviewed on-line open-access journal at http://www.siamb.org.il. To read papers free of charge, please register online at registration form.

Sale of $I J A$ papers is strictly forbidden.

\title{
Enterobacter aerogenes: an Emerging Pathogen for Enteritis in Farmed Channel Catfish Ictalurus punctatus
}

\author{
Haipeng $\mathrm{CaO}^{1}$, Jian $\mathrm{An}^{2}$, Renjian $\mathrm{Ou}^{3}$, Liqun $\mathrm{Lu}^{1}$, Xiaohui $\mathrm{Ai}^{4 *}$, Yibin \\ Yang $^{4 *}$
}

The first two authors contributed equally to this work.

\author{
1. National Pathogen Collection Center for Aquatic Animals, Shanghai \\ Ocean University, Shanghai 201306, P.R. China. \\ 2. Marine and Fisheries Research Institute of Lianyungang, Lianyungang, \\ Jiangsu 222044, P.R. China. \\ 3. Longquanyi District Rural Development and Forestry Agency, Chengdu \\ 610100, P.R. China. \\ 4. Yangtze River Fisheries Research Institute, Chinese Academy of Fishery \\ Sciences, Wuhan Hubei 430223, P.R. China.
}

Keywords: Enterobacter aerogenes; Ictalurus punctatus; enteritis; antibiotic susceptibility.

\begin{abstract}
Enteritis has caused significant economic losses in farmed channel catfish Ictalurus punctatus. Yet information is limited on Enterobacter aerogenes as a potential causal agent for enteritis in channel catfish. In this study, a virulent strain, temporarily named HT2, was isolated from diseased channel catfish suffering from enteritis, identified phenotypically and molecularly as E. aerogenes. A phylogenetic tree was constructed to examine isolate HT2 and compare it to other known isolates. In addition, isolate HT2 is apparently susceptible to aminoglycosides and quinolones, drugs for veterinary use in aquaculture as seen when screened against a range of common antibiotics. To the best of our knowledge, this is the first report of $E$. aerogenes as a pathogen causing enteritis in farmed channel catfish.
\end{abstract}

\footnotetext{
* Corresponding author. Tel: +862781780223; Fax: +862781780223; Email: yang19890923@yeah.net.
} 


\section{Introduction}

The channel catfish Ictalurus punctatus is an important freshwater fish species widely cultivated in Brazil, China, Cuba, Mexico, Russia and the USA (Pool, 2007). In particular, since its successful introduction in China in 1984, China's channel catfish industry has grown rapidly and is very profitable (Yan et al., 2013). Its production increased to over 260,000 tons in 2015 (Ministry of Agriculture of China, 2016). However, enteritis has caused significant economic problems in the channel catfish industry globally (Ma, 2010). Hence, more attention should be paid to this disease to ensure the development of a sustainable farming industry.

To date, several bacterial pathogens such as Aeromonas hydrophila (Zheng et al., 2012), Edwardsiella tarda (Yu et al., 2009) and Streptococcus iniae (Chen et al., 2011) have been reported to cause enteritis in freshwater fish,. However, limited information is available on the identification of Enterobacter aerogenes as a causal agent for enteritis in Channel Catfish Ictalurus punctatus. In the present study, an E. aerogenes strain was isolated from cage-reared channel catfish suffering from enteritis in Nanning China during August 2016. The aim of this study was to establish pathogenicity, characterize the phenotype, taxonomic position, and antibiotic sensitivity of this strain. As far as we know, this is the first report of $E$. aerogenes-as a pathogen causing enteritis in farmed channel catfish.

\section{Materials and methods}

Fish samples. Eighteen diseased channel catfish averaging $50.26 \pm 1.06 \mathrm{~g}$ suffering from enteritis were sampled from a catfish farm in Nanning China during August 2016. The farm had 310 square meters of cages with juvenile channel catfish stocked at an initial rearing density of 400 juveniles per square meter. The water quality during the disease outbreak was $\mathrm{pH} 7.51,0.09 \mathrm{mg} / \mathrm{L}$ total ammonia, $0.005 \mathrm{mg} / \mathrm{L}$ nitrite, and $7.56 \mathrm{mg} / \mathrm{L}$ dissolved oxygen. Diseased samples were placed in sterile bags, kept in ice and transported to the laboratory.

Bacterial isolation. Each sampled diseased channel catfish was externally disinfected with $75 \%$ alcohol and dissected. Before conducting a careful examination for parasites and viruses as described by Yang \& Yang (2013) and Zeng et al. (2013), 0.05g affected intestine of each diseased fish was removed and streaked onto nutrient agar (NA) plates (Sinopharm Chemical Reagent Co., Ltd.). After incubation for $24 \mathrm{~h}$ at $28^{\circ} \mathrm{C}$, the dominant uniform isolates were purified by streaking and re-streaking onto NA plates. Pure isolates of the dominant colonies were stored at $-80^{\circ} \mathrm{C}$ supplemented with $15 \%$ glycerol. A representative of the dominant isolates, temporarily named $H T 2$, was further characterized in the present study.

Bacterial identification

Molecular identification. The extraction of genomic DNA from isolate HT2, as well as PCR amplification and sequencing of its 16S rRNA gene were performed according to our previous study (Cao et al., 2010). The near complete 16S rRNA gene sequence was assembled using Editseq and Seqman in DNAstar software. A search was performed in the National Centre for Biotechnology Information (NCBI) database for sequence homology using the Basic Local Alignment Search Tool (BLAST) program. A phylogenetic tree from the near complete 16S rRNA gene sequence of the isolate and its homologous sequences was constructed using the neighbor-joining method.

Phenotypic identification. Isolate HT2 was identified phenotypically using API 32E test strips as recommended by Lehner et al. (2006). The test strip was incubated at $37^{\circ} \mathrm{C}$ and observed after $24 \mathrm{~h}$ against the API identification index. The strain ATCC 13048 of $E$. aerogenes was used as the control.

Bacterial virulence assay. Bacterial virulence was examined by experimentally injecting healthy cultured channel catfish. One hundred healthy fish averaging $100 \pm 10 \mathrm{~g}$ were obtained from Baishazhou fishery Co. Ltd., in Wuhan China. Their health status was evaluated according to guidelines described by Zheng et al. (2012). The experimental fish were acclimated in ten replicate aquaria (each stocked with ten fish) supplied with 50 $\mathrm{L}$ of aerated filtered farming water at $26^{\circ} \mathrm{C}$ for 14 days. Prior to the bacterial virulence assay, isolate HT2 was inoculated onto NA plate, incubated at $28^{\circ} \mathrm{C}$ for $24 \mathrm{~h}$, and washed with normal saline into a sterile tube. Cell density was determined by counting colony 
forming units (CFU) after a ten-fold serial dilution in sterile distilled water. Two replicates of ten healthy fish were injected intraperitoneally with $0.2 \mathrm{~mL}$ of isolate $\mathrm{HT2}$ at concentrations of $3.2 \times 10^{4} \mathrm{CFU} / \mathrm{mL}$ to $3.2 \times 10^{7} \mathrm{CFU} / \mathrm{mL}$. Another two replicates of ten healthy fish exposed to the same experimental conditions and injected intraperitoneally with $0.2 \mathrm{~mL}$ of normal saline served as control. The experimental fish were kept at $26^{\circ} \mathrm{C}$ and observed daily for seven days without feeding and water change. Dead fish were immediately removed and sampled to confirm if mortality was caused specifically by the injected isolate. The mean lethal dose $\left(L_{50}\right)$ value is calculated according to the graphical probit method recommended by Ogbuagu \& Iwuchukwu (2014).

Antibiotic sensitivity assay. The antibiotic sensitivity of isolate HT2 was assayed on NA plates using the Kirby-Bauer disk diffusion method as described by Joseph et al. (2011). Twenty two antibiotic discs were acquired from Hangzhou Tianhe Microorganism Reagent Co., Ltd. The inhibition zones were measured after a $24 \mathrm{~h}$ incubation period at $28^{\circ} \mathrm{C}$. The antibiotic susceptibility was determined according to the manufacturer's guidelines.

\section{Results}

Bacterial identification. A dominant isolate HT2 was isolated from the diseased farmed channel catfish and identified by molecular and phenotypic methods as $E$. aerogenes. Its near complete 16S rRNA gene sequence (1400 nucleotides) was submitted to GenBank database with the accession no. KY264130. A similarity of $99 \%$ was observed in the $16 \mathrm{~S}$ rRNA gene sequence between the HT2 isolate and other $E$. aerogenes isolates from the GenBank database. The phylogenetic tree confirms that the isolate HT2 was identified with $E$. aerogenes strain (Figure 1 ). This is again confirmed by the phenotypic features as E. aerogenes (Table 1 ) with $100 \%$ identity compared to the reference strain. No parasites and viruses were detected in the diseased channel catfish from which the isolate HT2 was obtained.

Figure 1. A $16 \mathrm{~S}$ rRNA gene tree of 16 known bacteria and the HT2 isolate constructed using the neighbourjoining method. The bootstrap values (\%) are shown besides the clades, accession numbers are indicated beside the names of strains, and scale bars represent distance values.

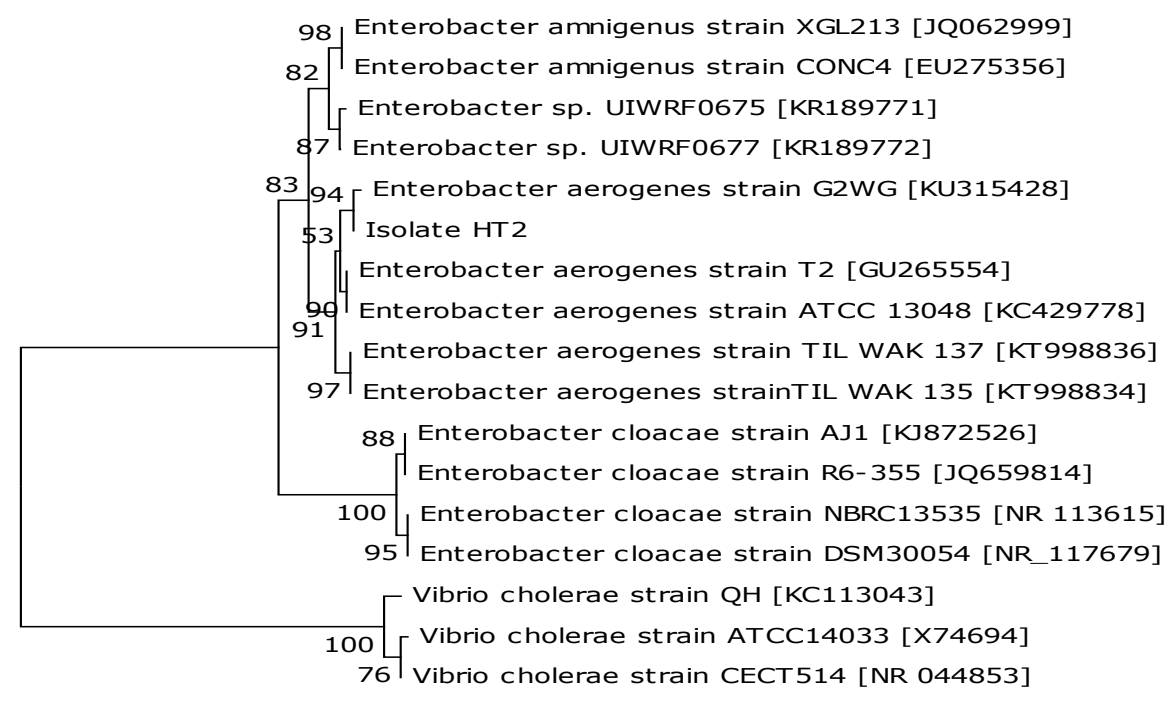

$\longmapsto .01$ 
Table 1. Phenotypic characteristics of isolate HT2.

\begin{tabular}{|c|c|c|}
\hline \multirow{2}{*}{ Tests } & \multicolumn{2}{|c|}{ Reaction } \\
\hline & HT2 & ATCC 13048 \\
\hline Arginine dihydrolase & $\mathrm{R}^{-}$ & $\mathrm{R}^{-}$ \\
\hline Lysine decarboxylase & $\mathrm{R}^{+}$ & $\mathrm{R}^{+}$ \\
\hline Lipase & $\mathrm{R}^{-}$ & $\mathrm{R}^{-}$ \\
\hline L-aspartate aminase & $\mathrm{R}^{+}$ & $\mathrm{R}^{+}$ \\
\hline $\mathrm{N}$-acetyl- $\beta$-glucosaminidase & $\mathrm{R}^{-}$ & $\mathrm{R}^{-}$ \\
\hline a-galactosidase & $\mathrm{R}^{+}$ & $\mathrm{R}^{+}$ \\
\hline a-glucosaccharase & $\mathrm{R}^{-}$ & $\mathrm{R}^{-}$ \\
\hline a-maltosidase & $\mathrm{R}^{-}$ & $\mathrm{R}^{-}$ \\
\hline$\underline{\beta}$-galactosidase & $\mathrm{R}^{+}$ & $\mathrm{R}^{+}$ \\
\hline$\underline{\beta}$-glucosaccharase & $\mathrm{R}^{+}$ & $\mathrm{R}^{+}$ \\
\hline$\underline{\beta}$-glucuronidase & $\mathrm{R}^{-}$ & $\mathrm{R}^{-}$ \\
\hline Úrease & $\mathrm{R}^{-}$ & $\mathrm{R}^{-}$ \\
\hline Orinithine decarboxylase & $\mathrm{R}^{+}$ & $\mathrm{R}^{+}$ \\
\hline Indole production & $\mathrm{R}^{-}$ & $\mathrm{R}^{-}$ \\
\hline Malonate utilization & $\mathrm{R}^{+}$ & $\mathrm{R}^{+}$ \\
\hline \multicolumn{3}{|l|}{ Acid production from } \\
\hline Adonitol & $\mathrm{R}^{+}$ & $\mathrm{R}^{+}$ \\
\hline Galacturonic acid & $\mathrm{R}^{+}$ & $\mathrm{R}^{+}$ \\
\hline Inositol & $\mathrm{R}^{+}$ & $\mathrm{R}^{+}$ \\
\hline L-arabinose & $\mathrm{R}^{+}$ & $\mathrm{R}^{+}$ \\
\hline L-arabitol & $\mathrm{R}^{-}$ & $\mathrm{R}^{-}$ \\
\hline L-rhamnose & $\mathrm{R}^{+}$ & $\mathrm{R}^{+}$ \\
\hline D-arabitol & $\mathrm{R}^{+}$ & $\mathrm{R}^{+}$ \\
\hline D-cellobiose & $\mathrm{R}^{+}$ & $\mathrm{R}^{+}$ \\
\hline D-glucose & $\mathrm{R}^{+}$ & $\mathrm{R}^{+}$ \\
\hline D-maltose & $\mathrm{R}^{+}$ & $\mathrm{R}^{+}$ \\
\hline D-mannitol & $\mathrm{R}^{+}$ & $\mathrm{R}^{+}$ \\
\hline D-sorbitol & $\mathrm{R}^{+}$ & $\mathrm{R}^{+}$ \\
\hline D-sucrose & $\mathrm{R}^{+}$ & $\mathrm{R}^{+}$ \\
\hline D-trehalose & $\mathrm{R}^{+}$ & $\mathrm{R}^{+}$ \\
\hline 5-ketone-potassium gluconate & $\mathrm{R}^{-}$ & $\mathrm{R}^{-}$ \\
\hline Palatinose & $\mathrm{R}^{+}$ & $\mathrm{R}^{+}$ \\
\hline Sodium pyruvate & $\mathrm{R}^{-}$ & $\mathrm{R}^{-}$ \\
\hline
\end{tabular}

$\mathrm{R}^{+}$: positive reaction; $\mathrm{R}^{-}$: negative reaction.

Isolate HT2 was virulent to channel catfish with a $\mathrm{LD}_{50}$ value of $1.18 \times 10^{6} \mathrm{CFU} / \mathrm{mL}$ (Table 2). The infected fish exhibited signs of enteritis similar to those seen in the originally diseased fish (Figure 2). When fish were injected with a concentration of 3.2 $\times 10^{7} \mathrm{CFU} / \mathrm{mL}$, high mortality was observed. Isolate $\mathrm{HT} 2$ could be re-isolated from experimentally morbid fish. No clinical signs or mortality were noted in the control fish.

Figure 2. Pathological symptoms of the farmed channel catfish suffering from enteritis: (a) arrow shows abdominal distension; (b) arrow shows intestinal hyperaemia.

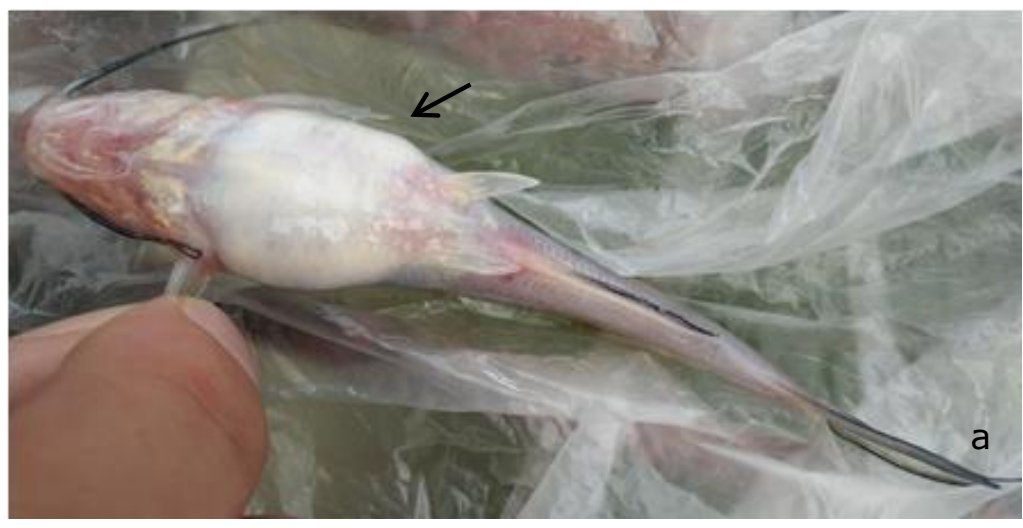




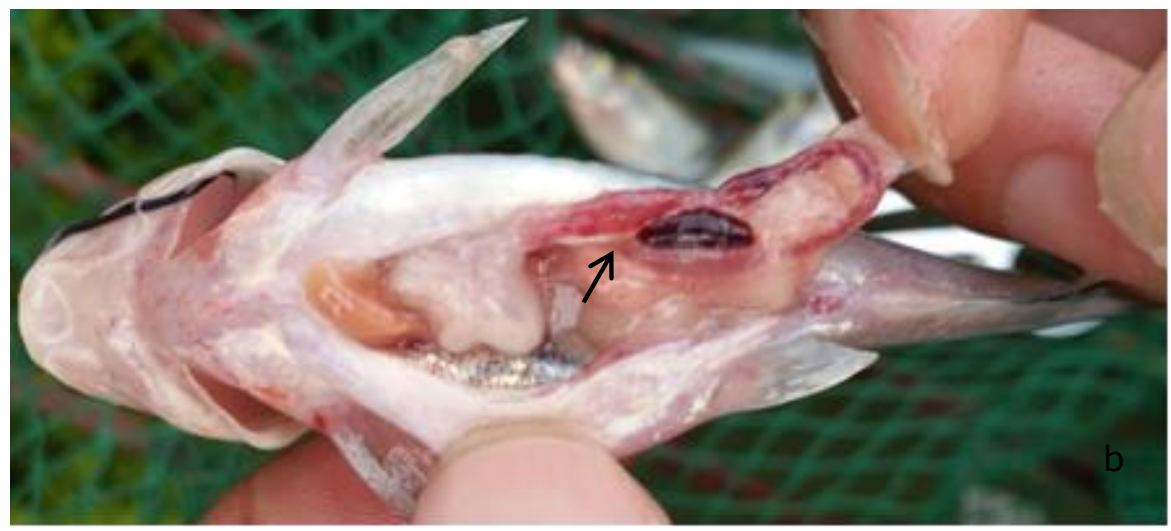

Table 2. Cumulative mortality of experimental channel catfish infected by the isolate HT2.

\begin{tabular}{|c|c|c|c|c|c|c|c|c|c|c|c|}
\hline \multirow{2}{*}{ Group } & \multirow{2}{*}{$\begin{array}{l}\text { Concentration } \\
(C F U / m L)\end{array}$} & \multirow{2}{*}{$\begin{array}{l}\text { Fish } \\
\text { no. }\end{array}$} & \multicolumn{7}{|c|}{$\begin{array}{l}\text { Dead fish no. on day after } \\
\text { challenge }\end{array}$} & \multirow{2}{*}{$\begin{array}{l}\text { Average } \\
\text { cumulative } \\
\text { mortality (\%) }\end{array}$} & \multirow{2}{*}{$\begin{array}{l}\text { LD } D_{50} \text { value } \\
(C F U / m L)\end{array}$} \\
\hline & & & 1 & 2 & 3 & 4 & 5 & 6 & 7 & & \\
\hline \multirow{2}{*}{ Control } & \multirow{2}{*}{0} & 10 & 0 & 0 & 0 & 0 & 0 & 0 & 0 & \multirow{2}{*}{0} & \multirow{10}{*}{$1.18 \times 10^{6}$} \\
\hline & & 10 & 0 & 0 & 0 & 0 & 0 & 0 & 0 & & \\
\hline \multirow{2}{*}{ Treatment 1} & \multirow{2}{*}{$3.2 \times 10^{4}$} & 10 & 0 & 0 & 0 & 0 & 1 & 0 & 0 & \multirow{2}{*}{10} & \\
\hline & & 10 & 0 & 0 & 0 & 1 & 0 & 0 & 0 & & \\
\hline \multirow{2}{*}{ Treatment 2} & \multirow{2}{*}{$3.2 \times 10^{5}$} & 10 & 1 & 2 & 0 & 0 & 0 & 0 & 0 & \multirow{2}{*}{30} & \\
\hline & & 10 & 1 & 1 & 1 & 0 & 0 & 0 & 0 & & \\
\hline \multirow{2}{*}{ Treatment 3} & \multirow{2}{*}{$3.2 \times 10^{6}$} & 10 & 3 & 2 & 1 & 1 & 0 & 0 & 0 & \multirow{2}{*}{65} & \\
\hline & & 10 & 2 & 1 & 2 & 0 & 1 & 0 & 0 & & \\
\hline \multirow{2}{*}{ Treatment 4} & \multirow{2}{*}{$3.2 \times 10^{7}$} & 10 & 4 & 2 & 1 & 2 & 1 & 0 & 0 & \multirow{2}{*}{100} & \\
\hline & & 10 & 6 & 2 & 1 & 1 & 0 & 0 & 0 & & \\
\hline
\end{tabular}

Antibiotic susceptibility. The antibiotic sensitivity of isolate HT2 is shown in Table 3. The data indicate that the isolate HT2 is sensitive to amikacin, ciprofloxacin, enrofloxacin, gentamycin, levofloxacin, neomycin, norfloxacin, tobramycin, intermediately sensitive to kanamycin, streptomycin, and resistant to the $\beta$-lactam, chloramphenicol, lincosamides, macrolides, nitrofuran, sulfonamides, tetracyclines antibiotics. This suggests that the isolate HT2 has not developed resistance to aminoglycosides and quinolones antimicrobials.

Table 3. Susceptibility of isolate HT2 to antibiotics.

\begin{tabular}{|c|c|c|}
\hline Antibiotics & $\begin{array}{l}\text { Content } \\
(\mu g / \text { disc })\end{array}$ & Inhibition zone diameter $(\mathrm{mm})$ \\
\hline Amikacin & 30 & $21.95 \pm 0.09^{\mathrm{S}}$ \\
\hline Cefradine & 30 & $0 \pm 0^{R}$ \\
\hline Cefotaxime & 30 & $0 \pm 0^{R}$ \\
\hline Chloramphenicol & 300 & $10.50 \pm 0.47^{R}$ \\
\hline Ciprofloxacin & 5 & $21.08 \pm 0.08^{\mathrm{S}}$ \\
\hline Clindamycin & 2 & $0 \pm 0^{R}$ \\
\hline Doxycycline* & 30 & $8.94 \pm 0.14^{R}$ \\
\hline Enrofloxacin ${ }^{*}$ & 5 & $17.27 \pm 0.32^{\mathrm{S}}$ \\
\hline Erythrocin & 15 & $11.06 \pm 0.15^{\mathrm{R}}$ \\
\hline Florfenicol* $^{*}$ & 75 & $0 \pm 0^{R}$ \\
\hline Furazolidone & 300 & $12.29 \pm 0.25^{\mathrm{R}}$ \\
\hline Gentamycin & 10 & $18.04 \pm 0.08^{\mathrm{S}}$ \\
\hline Kanamycin & 30 & $15.77 \pm 0.29^{\mathrm{I}}$ \\
\hline Levofloxacin & 5 & $22.82 \pm 0.19^{s}$ \\
\hline Neomycin* ${ }^{*}$ & 30 & $18.81 \pm 0.34^{\mathrm{s}}$ \\
\hline Norfloxacin & 10 & $27.00 \pm 0.16^{S}$ \\
\hline Oxacillin & 1 & $0 \pm 0^{R}$ \\
\hline Penicillin & $10 I U$ & $0 \pm 0^{R}$ \\
\hline Rifampicin & 5 & $0 \pm 0^{R}$ \\
\hline Streptomycin & 10 & $13.05 \pm 0.16^{\mathrm{I}}$ \\
\hline Sulfamethoxazole* & 300 & $0 \pm 0^{R}$ \\
\hline Tobramycin & 10 & $22.92 \pm 0.21^{s}$ \\
\hline
\end{tabular}

Data are presented as the mean \pm standard deviation; ${ }^{\text {SSensitive; }}{ }^{\text {I Intermediately sensitive; }}$

${ }^{R}$ Resistant.*Antibiotics for aquaculture use. 


\section{Discussion}

The association of Enterobacter species in aquaculture has been documented with mortality in Mugil cephalus (Sekar et al., 2008) and Pangasianodon hypophthalmus (Kumar et al., 2013). However, there is limited information on Enterobacter species as causal organisms for enteritis in cultured channel catfish. In this study, we tested and proved pathogenicity of $E$. aerogenes $\mathrm{HT} 2$, characterized the phenotype, taxonomic position, and antibiotic susceptibility of $E$. aerogenes HT2. To our knowledge, this is the first report of an $E$. aerogenes pathogen as a causative agent for enteritis in farmed channel catfish.

The pathogenesis of fish enteritis is complex and multi-factorial (Lee et al., 2002). It could be induced in fish by intraperitoneal injection with $E$. aerogenes, a well-recognized protease producing opportunistic pathogen (Kim et al., 1984; Galani et al., 2007). In the present study, $E$. aerogenes $\mathrm{HT} 2$ isolate attained $\mathrm{LD}_{50}$ mortality in healthy channel catfish when challenged with a concentration of $1.18 \times 10^{6} \mathrm{CFU} / \mathrm{mL}$. This further demonstrates the potential threat of HT2 to channel catfish farming. Apart from the virulence of the HT2 isolate, there might be other secondary factors that induce enteritis in channel catfish, such as the use of contaminated feed and the misuse of feed additives (Cao et al., 2016); these should also be raised as concerns.

Multiple drug resistance in Enterobacter species has been reported to $\beta$-lactam, chloramphenicol, lincosamides, macrolides antibiotics (Davin-Regli \& Pagès, 2015; Ghisalberti et al., 2005; Stock \& Wiedemann, 2002). The HT2 isolate in our study exhibited the similar multidrug-resistant susceptibility to these antimicrobials. Besides, the HT2 isolate also showed resistance to doxycycline and sulfamethoxazole used in fish farming regions, suggesting that the outbreak of this disease may have resulted from abuse of these antibiotics.

In conclusion, we believe that the present study reports an $E$. aerogenes isolate as a causal organism of enteritis in cultured channel catfish for the first time. The pathogenicity of the HT2 isolate supports the claim that this infection is an emerging threat in channel catfish farming.

\section{Acknowledgments}

This work has been financially supported by Minhang District Industry-UniversityResearch Institute Program, Shanghai China (No. 2016MH252) and Special Fund for Agro-scientific Research in the Public Interest (No. 201503108-CC-1, 201203085). We also thank Wenqi Hou for bacterial isolation and identification in this work.

\section{References}

Cao H., He S., Li Y., Yang Y., Ai X., 2016. Hafnia alvei: a pathogen causing infectious intussusception syndrome (IIS) in farmed channel catfish Ictalurus punctatus. Isr. J. Aquacult.-Bamidgeh, IJA_68.2016.1305.

Cao H., He S., Lu L., Hou L., 2010. Characterization and phylogenetic analysis of the bitrichous pathogenic Aeromonas hydrophila isolated from diseased Siberian sturgeon. Isr. J. Aquacult.-Bamidgeh, 62(3):181-188.

Chen D., Wang K., Geng Y., Wang J., Huang X., He M., 2011. Pathological changes in cultured channel catfish Ictalurus punctatus spontaneously infected with Streptococcus iniae. Dis Aquat Org., 95(3):203-208.

Davin-Regli A., Pagès J.M., 2015. Enterobacter aerogenes and Enterobacter cloacae; versatile bacterial pathogens confronting antibiotic treatment. Frontiers in Microbiol., 6:392.

Galani I., Souli M., Koratzanis E., Koratzanis G., Chryssouli Z., Giamarellou H., 2007. Emerging bacterial pathogens: Escherichia coli, Enterobacter aerogenes and Proteus mirabilis clinical isolates harbouring the same transferable plasmid coding for metallo- $\beta$-lactamase VIM-1 in Greece. J Antimicrob Chemo., 59(3):578-579.

Ghisalberti D., Masi M., Pagès J.M., Chevalier J., 2005. Chloramphenicol and expression of multidrug efflux pump in Enterobacter aerogenes. Biochem Biophys Res Comm., 328(4):1113-1118. 
Joseph N.M., Sistla S., Dutta T.K., Badhe A.S., Rasitha D., Parija S.C., 2011. Reliability of Kirby-Bauer disk diffusion method for detecting meropenem resistance among non-fermenting gram-negative bacilli. Indian J Pathol Microbiol., 54(3):556-560.

Kim O.H., Mikami M., Miura H., 1984. Degradation of meat proteins under the chilled storage condition by Enterobacter aerogenes, and purification and properties of it's extracellular protease. Research Bulletin of Obihiro University Series I, 13(4):247-256.

Kumar K., Prasad K.P., Raman R.P., Kumar S., Purushothaman C.S., 2013. Association of Enterobacter cloacae in the mortality of Pangasianodon hypophthalmus (Sauvage, 1878) reared in culture pond in Bhimavaram, Andhra Pradesh, India. Indian J Fisheries, 60(3):147-149.

Lee K.K., Liu P.C., Chuang W.H., 2002. Pathogenesis of gastroenteritis caused by Vibrio carchariae in cultured marine fish. Mar Biotechnol., 4:267-277.

Lehner A., Nitzsche S., Breeuwer P., Diep B., Thelen K, Stephan R., 2006. Comparison of two chromogenic media and evaluation of two molecular based identification systems for Enterobacter sakazakii detection. BMC Microbiology, 6:15-22.

Ma S., 2010. Etiology and control of intestinal diseases in Ictalurus punctatus. Current Fisheries, 9 : 50-51.

Ministry of Agriculture of China, 2016. China Fishery Statistical Yearbook. Beijing: China Agriculture Press, $31 \mathrm{pp}$.

Ogbuagu D.H., Iwuchukwu E.I., 2014. Evaluation of the toxicity of three hair shampoos on the catfish (Clarias gariepinus) fingerlings. Appl Ecol Env Sci., 2(3):86-89.

Pool T.K., 2007. Channel catfish review: life-history, distribution, invasion dynamics and current management strategies in the Pacific Northwest. Washington, USA: University of Washington, 12pp.

Sekar V.T., Santiago T.C., Vijayan K.K., Alavandi S.V., Raj V.S., Rajan J.J.S., Sanjuktha M., Kalaimani N., 2008. Involvement of Enterobacter cloacae in the mortality of the fish, Mugil cephalus. Letters in Applied Microbiology, 46(6):667-672.

Stock I., Wiedemann B., 2002. Natural antibiotic susceptibility of Enterobacter aminigenus, Enterobacter cancerogenus, Enterobacter gergoviae and Enterobacter sakazakii strains. Clin Microb Infect., 8(9):564-578.

Yan C., Xiao Y., Li L., 2013. Current status of the world catfish industry and reconsideration for its market positioning. China Fisheries, 6:36-40.

Yang, S., Yang, Z., 2013. Preliminary studies on diagnosis, prevention and treatment of parasitic diseases in ornamental fishes. Chinese J Anim Infect Dis., 5: 57-62.

Yu J.H., Han J.J., Park K.S., Park K.H., Park S.W., 2009. Edwardsiella tarda infection in Korean catfish, Silurus asotus, in a Korean fish farm. Aquacult Res., 41(1):19-26.

Zeng, W., Wang, Q., Wang, Y., Liu, C., Tan, A., Shi, C., Wu, S., 2013. Isolation and characterization of a rhabdovirus from snakehead fish (Ophicephalus striatus). J Fisheries of China, 9: 1416-1424.

Zheng W., Cao H., Yang X., 2012. Grass carp (Ctenopharyngodon idellus) infected with multiple strains of Aeromonas hydrophila. African J Microb Res., 6(21):4512-4520. 